\title{
Imágenes en AVE isquémico, un ejemplo de la necesidad del radiólogo disponible
}

\section{Juan Pablo Cruz Quiroga'*}

1. Radiólogo. Pontificia Universidad Católica de Chile. Santiago, Chile.

La terapia para el AVE isquémico ha sido uno de esos tratamientos en medicina que ha visto un desarrollo vertiginoso avalado por evidencia recolectada en corto plazo y de alta calidad, demostrando una magnitud de efecto terapéutico pocas veces vista en medicina. Es así como el número necesario a tratar (NNT) para obtener el resultado medido en pacientes seleccionados para trombectomía puede llegar a ser tan bajo como 2,8, como fue visto en el DAWN trial. Como para tener una noción comparativa, el NNT estimado de antibióticos para manejo de la sepsis es de 4, y el NNT de NASCET, uno de los estudios más efectivos visto en manejo de la estenosis carotidea sintomática, fue de 7. El efecto de estos estudios ha sido tan grande, que la trombectomía ya forma parte de las guías clínicas de manejo de AVE isquémico de la American Heart Association (AHA) y ha significado una carga importante para los equipos de terapia endovascular. Además, ha planteado un desafío para los servicios de salud de distintos países para poder implementar esta terapia, ya que los terapeutas neurovasculares y las unidades dedicadas al manejo de AVE son comparativamente muy escasas, lo que conlleva una poca cobertura territorial.

¿Cuál es la importancia y la implicancia de los resultados de los ensayos de trombectomía para los radiólogos y servicios de radiología? La selección de pacientes para terapia depende en gran medida de los hallazgos en imágenes. Los parámetros que deben ser evaluados son la presencia de oclusión proximal, la extensión del infarto y, en aquellos en ventana terapéutica extendida (6-24 hrs), la presencia de tejido rescatable (ya sea directamente por técnicas perfusión o por "missmatch" entre tamaño de infarto y magnitud de déficit neurológico). Por estas razones los servicios de radiología de hospitales de referencia que manejen AVE isquémico con trombolisis endovenosa deben apuntar a tener al menos la disponibilidad 24/7 de angio-TC y, aquellos con capacidad de trombectomía, perfusión por TC para la selección de pacientes en ventana extendida. La disponibilidad de RM 24/7 es una realidad lejana en los hospitales del servicio público, pero debe ser también un objetivo deseable en el futuro al menos para los que sean referencia en manejo integral del ictus. Con esto en mente, si es que tenemos los equipos físicos y humanos para la adquisición de imágenes en este escenario clínico, se debe contar con el personal calificado para la interpretación de éstas en un lapso corto, para que sea relevante en el proceso de toma de decisiones. Si bien esta responsabilidad cae teóricamente en los neuro-radiólogos y existen softwares automatizados para análisis de las imágenes en stroke, ambos recursos son limitados ya sea por número de profesionales o por el costo asociado. Es así como se ha empezado a considerar que aquellos radiólogos que hacen o se dedican a urgencias, debiesen estar familiarizados con los conceptos y los criterios de selección para la rápida interpretación y el post proceso necesario de las imágenes para entregar una opinión confiable en tiempos que permitan influir en la cadena diagnóstica y terapéutica. Puede parecer como un desafío sobrecogedor para los radiólogos trabajando en horario no hábil, pero con criterios claros, buena comunicación con los equipos tratantes, capacidad de entrega de informes abreviados y la disponibilidad de subespecialistas para consultar aquellos casos más desafiantes y para una segunda revisión para informe definitivo, se puede lograr un buen entendimiento y capacidad interpretativa en aquel subgrupo de pacientes con AVE isquémico y oclusión arterial proximal para diferenciar aquellos candidatos a trombectomía mecánica. 